\title{
Multi-dimensional Soundscape Interaction Design at Xi'an Small Wild Goose Pagoda
}

\author{
Yi Wang ${ }^{1}$, Qin Song ${ }^{1}$, and Rongchuan $\mathrm{Li}^{1}{ }^{1}{ }^{*}$ \\ ${ }^{1} \mathrm{Xi}$ 'an university of Technology, Xi; an, China
}

\begin{abstract}
Based on the analysis of the soundscape at Small Wild Goose Pagoda (also Xiao Yanta, according to its Chinese pronunciation) from the perspective of "audience-sound-environment", this article explores the audience's perception information of the "Yanta Morning Bell", the symbolic soundscape of the Small Wild Goose Pagoda. To probe audience's way of acquiring the perception information of the pagoda and the mode of constructing cultural contacts, this article starts with the uniqueness of the soundscape at the Small Wild Goose Pagoda, incorporating visual, hearing, touch and other interactive forms. By immersive experience, audiences can receive cultural information and enrich their cultural knowledge. This study hopes to provide new ideas for the multi-dimensional soundscape interaction design at Small Wild Goose Pagoda.
\end{abstract}

\section{Introduction}

When talking about soundscape, their visual effects are unavoidably noticed by people at the first sight, such as the color, shape, and style. With the development of society, people are not satisfied with visual enjoyment only, they prefer multi-sensory and multi-channel integration experience with different interactions. A good soundscape design can not only meet people's visual needs, but also let them feel unique elements and culture of a specific area. Therefore, to facilitate the development of historical sites and help people better understand the history, this article discussed how to increase historical and cultural elements in the multi-dimensional interaction design of soundscape with Xi'an Small Wild Goose Pagoda as the design object.

\section{Literature of soundscape}

\subsection{Current study on soundscape}

The word "soundscape" was first proposed by a Finnish geographer Granoe in 1929. Soundscape is the acoustic environment as perceived by humans or society. It takes the word "landscape" which originated from the German word "landxchaft" as the reference [1]. In China, systematic research on soundscape design started from the publication of the article Overview of Soundscape by Li Guoqi, which has aroused attention and resonated among the academic field. The research on soundscape further probed the ideas, specific design methods and characteristics of soundscape design ${ }^{[2]}$ based on the "human-sound-environment" interrelation.

Scholars have rich theoretical research on "soundscape" from different perspectives, and have initially formed different research directions. Studies by combining design research with sound research form a new interdisciplinary exploration as well as an attempt to integrate social science knowledge and technology, which can achieve a two-way breakthrough in the fields of design and sound ${ }^{[3]}$.

\subsection{Soundscape interaction design status in China and the rest of the world}

The contemporary research on soundscape design in China and the rest of the world develop rapidly. Different regional characteristics are gradually integrated into the system design of sound and environment, creating unique soundscapes and landscapes ${ }^{[4]}$ (Table 1).

It can be seen from Table 1 that the soundscape designs (3D shell sound effect room, drum wall, etc.) generally bring people auditory as well as visual enjoyment simultaneously, achieving the multidimensional interaction of soundscape. Multidimensional interaction enables soundscape design to integrate vision, hearing, touch, smell and taste, so that people can have immersive experience. However, soundscape design usually has a weak connection with regional culture and history, which makes the design lack of regional cultural differences. Floor piano and music fountain can be easily found in large shopping malls, parks, squares, subway stations and other places, making similar sounds.

Each historical site contains different historical culture. Therefore, when designing the soundscape of historical sites, we need to take into account the historical and cultural characteristics of different historical sites and design representative and unique soundscapes. 
Table1. Analysis of soundscape at home and abroad

\begin{tabular}{|c|c|c|c|c|c|c|c|c|}
\hline number & name & picture & region & Pronunciation & $\begin{array}{l}\text { Regional } \\
\text { culture }\end{array}$ & Interactivity & $\begin{array}{c}\text { Sensory } \\
\text { interactio } \\
n\end{array}$ & $\begin{array}{l}\text { Material } \\
\text { properties }\end{array}$ \\
\hline 1 & $\begin{array}{l}\text { 3D Shell } \\
\text { sound } \\
\text { room }\end{array}$ & & $\begin{array}{c}\text { U.S.A } \\
\text { ( NASA } \\
\text { orbital } \\
\text { Museum) }\end{array}$ & Natural wind & $\begin{array}{l}\text { The sound of } \\
\text { the sea }\end{array}$ & Participative & $\begin{array}{l}\text { vision } \\
\text { hearing }\end{array}$ & $\begin{array}{l}\text { Aluminum } \\
\text { sheet }\end{array}$ \\
\hline 2 & Flame & & $\begin{array}{l}\text { Britain } \\
\text { (Middlesbr } \\
\text { ough) }\end{array}$ & Natural wind & Middles Castle & $\begin{array}{c}\text { Non } \\
\text { Participative }\end{array}$ & $\begin{array}{l}\text { vision } \\
\text { hearing }\end{array}$ & $\begin{array}{l}\text { Anodized } \\
\text { aluminum } \\
\text { plate }\end{array}$ \\
\hline 3 & $\begin{array}{c}\text { The fallen } \\
\text { leaves }\end{array}$ & & $\begin{array}{r}\text { Germany } \\
\text { (Berlin } \\
\text { Memorial) }\end{array}$ & Human walking & $\begin{array}{l}\text { Jewish } \\
\text { Memorial }\end{array}$ & Participative & $\begin{array}{l}\text { Vision, } \\
\text { hearing, } \\
\text { touch }\end{array}$ & Sheet metal \\
\hline 4 & $\begin{array}{l}\text { A chair } \\
\text { for ears }\end{array}$ & & $\begin{array}{l}\text { Japan } \\
\text { (Park) }\end{array}$ & $\begin{array}{l}\text { Steel pipe } \\
\text { Voice } \\
\text { transmission }\end{array}$ & $\begin{array}{l}\text { Urban sound } \\
\text { collection }\end{array}$ & $\begin{array}{c}\text { Non } \\
\text { Participative }\end{array}$ & $\begin{array}{l}\text { vision } \\
\text { hearing }\end{array}$ & Metal tube \\
\hline 5 & $\begin{array}{l}\text { Piano } \\
\text { swing }\end{array}$ & & $\begin{array}{l}\text { Canada } \\
\text { (park) }\end{array}$ & $\begin{array}{l}\text { Electronic } \\
\text { phonation }\end{array}$ & $\begin{array}{c}\text { Park } \\
\text { Entertainment }\end{array}$ & Participative & $\begin{array}{l}\text { Vision, } \\
\text { hearing, } \\
\text { touch }\end{array}$ & Metal \\
\hline 6 & $\begin{array}{l}\text { Floor } \\
\text { piano }\end{array}$ & & $\begin{array}{l}\text { China } \\
\text { (Yantai) }\end{array}$ & $\begin{array}{l}\text { Electronic } \\
\text { phonation }\end{array}$ & $\begin{array}{l}\text { Shopping malls } \\
\text { and parks }\end{array}$ & Participative & $\begin{array}{l}\text { Vision, } \\
\text { hearing, } \\
\text { touch }\end{array}$ & $\begin{array}{l}\text { stainless } \\
\text { steel }\end{array}$ \\
\hline 7 & $\begin{array}{l}\text { Drum } \\
\text { Wall }\end{array}$ & & $\begin{array}{l}\text { China } \\
\text { (Xi'an) }\end{array}$ & $\begin{array}{l}\text { Take the } \\
\text { initiative }\end{array}$ & The Olympics & Participative & $\begin{array}{l}\text { Vision, } \\
\text { hearing, } \\
\text { touch }\end{array}$ & Leatherwear \\
\hline 8 & $\begin{array}{l}\text { Music } \\
\text { Fountain }\end{array}$ & & $\begin{array}{l}\text { China } \\
\text { (Xi'an) }\end{array}$ & $\begin{array}{l}\text { Electronic } \\
\text { phonation }\end{array}$ & $\begin{array}{c}\text { Big Wild } \\
\text { Goose Pagoda }\end{array}$ & $\begin{array}{c}\text { Non } \\
\text { participative }\end{array}$ & $\begin{array}{l}\text { vision } \\
\text { hearing }\end{array}$ & Metal \\
\hline
\end{tabular}

\subsection{Trend of interactive soundscape design highlighting regional cultural characteristics}

The concept of interaction originated from the interaction between human and computer in 1960s. With the development of interaction technology, the peopleoriented industrial design thinking mode enlarges the definition and application scope of interactive design.

The human-landscape interaction in soundscape includes the "invisibility" and "spatialization" of the interactive interface and the "time dimension" during practice. This "human-sound-field" interaction creates a dynamic situation, comprehensively stimulating people's multi-sensory experience, and enabling them to form the interaction or resonance between the invisible landscape culture and their own emotions in the specific cultural context of historical sites.

\section{Soundscape cultural elements extrac- -tion at Small Wild Goose Pagoda}

\subsection{Soundscape cultural origin of Small Wild Goose Pagoda}


Small Wild Goose Pagoda is an artistic heritage of Buddhist architecture of the Tang Dynasty (618-907). Bell sound, as one of the most common sounds in Buddhist culture, has special meanings. The bell sound at the Small Wild Goose Pagoda was regarded as one of the Eight Eight Outstanding Views of Ancient Chang'an by Zhu Jiyi, a poet of the Qing Dynasty (1636-1912), and it was named as "Yanta Morning Bell (meaning the morning bell chime sound at the Small Wild Goose Pagoda)". This is a typical soundscape in the early stage that we get to know.

\subsection{Color elements extracyion}

Built in the Tang Dynasty, the Small Wild Goose Pagoda was featured with typical color characteristics of that period. People in the Tang Dynasty preferred pure natural mineral color. The direct use of natural mineral color in works could manifest a sense of heaviness, showing a feeling of solemnness and the beauty of natural simplicity. As shown in Figure 1.
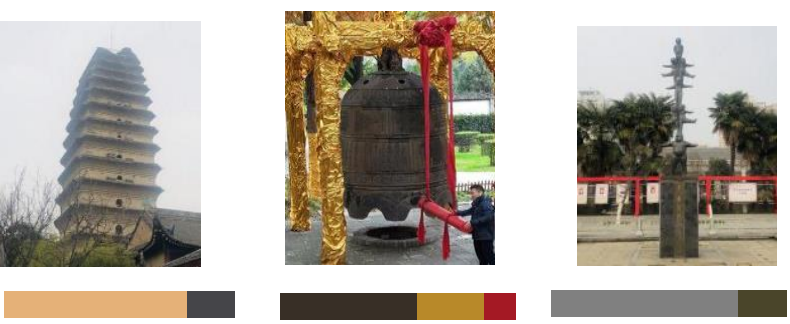

Fig. 1. color extraction of cultural elements of little wild goose pagoda

\subsection{Pattern elements extraction}

As one of the symbolic cultural signs of the Small Wild Goose Pagoda, the bell sound has irreplaceable emotional meanings to people. We extracted patterns on existing bells in the Small Wild Goose Pagoda. See Table 2 for details.

Table 2. Pattern extraction on bell

\begin{tabular}{cccc}
$\begin{array}{c}\text { Pattern } \\
\text { picture }\end{array}$ & $\begin{array}{c}\text { Pattern } \\
\text { extraction }\end{array}$ & $\begin{array}{c}\text { Combined } \\
\text { form }\end{array}$ & Moral \\
\hline & & Wave type & glorious \\
& & $\begin{array}{c}\text { Scatter } \\
\text { type }\end{array}$ & Good Fortune
\end{tabular}

\subsection{Textural elements extraction}

Define abbreviations and acronyms the first time they are used in the text, even after they have been defined in the abstract. Do not use abbreviations in the title unless they are unavoidable.As for the material texture, the Small Wild Goose Pagoda was mainly composed of natural materials because of traditional Chinese belief "the unity of man and nature". For example, the existing bells in the pagoda were made of bronze, on which were decorated different symbols. These bonze bells with low luster reflect a sense of simplicity and solemnness, together with the stone steles and ornaments displayed in the pagoda, bringing us the strength of history. As shown in Figure 2.
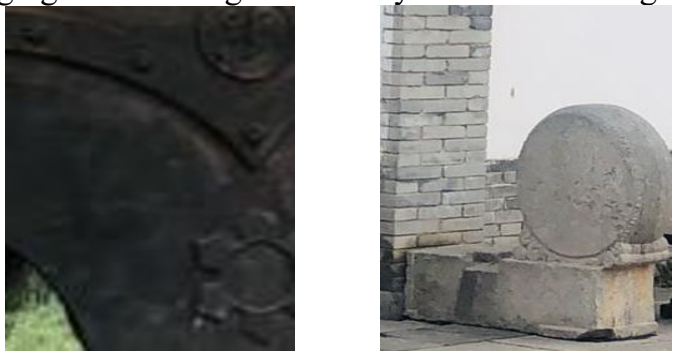

Fig. 2. Texture of materials in the Small Wild Goose Pagoda

\section{Multi-dimensional interactive expres- -sion of soundscape at Small Wild Goose Pagoda}

\subsection{Subjective sound environment perception mechanism of Small Wild Goose Pagoda}

The perceptual evaluation of sound environment is one of the elements of soundscape design, which is also the biggest difference from the traditional sound research ${ }^{[5]}$. Therefore, we carried out a walking perception experiment in the environment of "Yanta Morning Bell" to explore people's actual feelings when immersed in the environment. We analyzed the collected "feeling vocabulary" in factor analysis method to summarize the factors that brought the public feelings among people ${ }^{[6]}$.

\subsection{Collection of audiences' perceptions}

We have collected the adjectives used by people to describe their feelings to the "Yanta Morning Bell" through literature inquiry and audience interview. The 7Point Likert Scale was adopted to make a first-stage analysis to the perceptual vocabulary. Based on the correlation degree of semantics and words, there were 1 , $2,3,4,5,6$, and 7 points, with the two ends referring to "inconsistent" and "very consistent". It can be seen from the rotated component matrix below that the 13 sound perception words were classified into four categories, namely, spectacular, harmonious, solemn, and ethereal. Therefore, the soundscape design of Small Wild Goose Pagoda would be better to be "attached to" the large environment. See Table 3 for details.

Table 3. Rotated component matrix

\begin{tabular}{ccccc}
\hline & \multicolumn{4}{c}{ Ingredients } \\
\cline { 2 - 5 } & 1 & 2 & 3 & 4 \\
\hline Spectacular & .900 & & & \\
Magnificent & .854 & & \\
\hline
\end{tabular}




\begin{tabular}{ccccc}
\hline Pleasure & .674 & & \\
Prosperity & .604 & & \\
\hline Harmony & & .848 & \\
Towering & .766 & & \\
Simple and elegant & .662 & & \\
\hline Low & & .846 & \\
Fresh & & .815 & \\
Strong & & .535 & \\
Dark & & .505 & \\
\hline Ethereal & & & .778 \\
Clear & & & .759 \\
\hline
\end{tabular}

\section{Multi-dimensional soundscape intera- -ction design at Small Wild Goose Pagoda}

\subsection{Decision analysis on soundscape design at Small Wild Goose Pagoda}

Through analyzing the cultural contacts of the Small Wild Goose Pagoda, the soundscape design was considered to reflect a certain sense of ritual and involve some Buddhist elements, such as meditation in water. Audiences were expected to participate in the whole soundscape by ringing bells or stepping on slates to produce sounds, etc., which can enhance the interaction and audience's enjoyment. On bells, the carriers of bell sound, we can draw decorative patterns with the typical cultural characteristics of the Small Wild Goose Pagoda, such as the image of the Pagoda or patterns used to be cast on bells, etc., which will bring audience a strong visual impact. The multi-dimensional interaction design involving vision, hearing and touch, etc., can create a historical and cultural atmosphere in rituals and sound, which may leave a sound environment in audience's memory and enhance their enjoyment. Through the multi-sensory immersed experience, audiences can not only entertain themselves, but also understand the culture at the same time. Plan the tourist route as shown in figure 3. The design concept interactive contact is shown in figure 4.

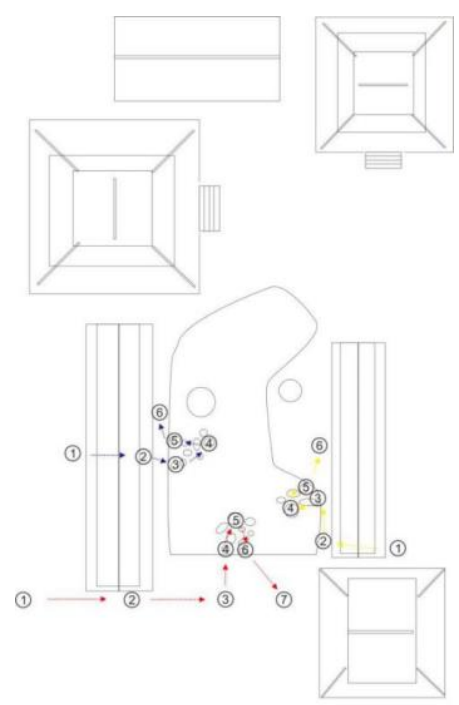

Fig. 3. Logical analysis diagram of participant behavior

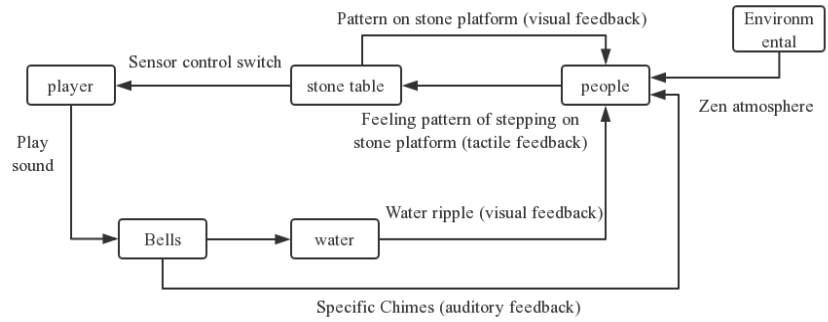

Fig. 4. Design concept interactive contact diagram

\subsection{Design description}

The soundscape design at the Small Wild Goose Pagoda takes the bell as the prototype and is decorated with elements relevant to the Tang Dynasty to enhance the visual cultural impact. The bell is placed in a landscape garden that highlights the Zen culture of Buddhism to increase audience's artistic conception. Because the physical propagation of the bell sound affects the flow of water, and the vibration of water causes different water waves, the sound will be visualized, and the audience can obviously feel the fluctuation of water when standing on stones in the water. The entire design enables the audience to not only hear the sound, but also see the sound and feel the sound, bringing the audience an immersive feeling, so that they can accept the cultural sense contained in the soundscape more easily. The perception flow chart is shown in figure 5 and the rendering is shown in figure 6.

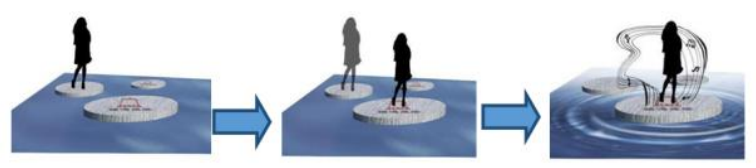

Fig. 5. Design perception flow chart 


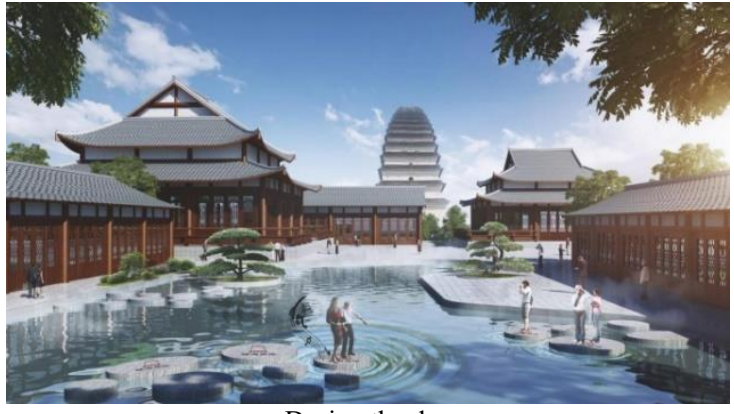

During the day

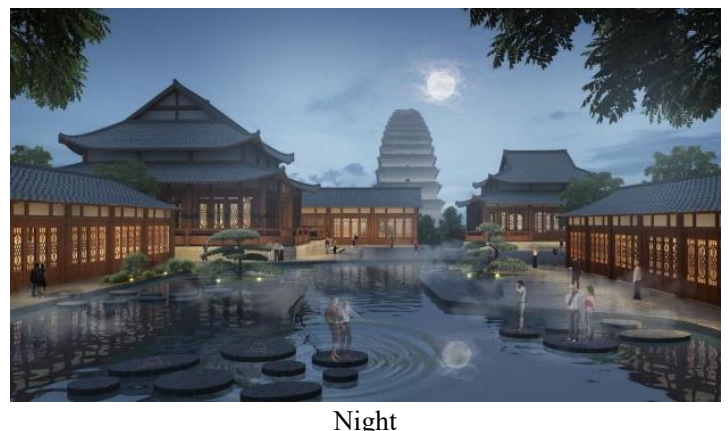

Fig. 6. Design rendering

\section{Conclusion}

The multi-dimensional soundscape interaction design at Small Wild Goose Pagoda attaches great importance on culture promotion. Comparing multi-sensory stimuli with people's cultural contacts of the Small Wild Goose Pagoda, the design meets the audience's different needs and increase the uniqueness of the soundscape. Based on the analysis of audience's perception, we can improve the cultural attributes in multi-dimensional interaction design of soundscape by grasping the cultural contacts of the Small Wild Goose Pagoda and incorporating multiple senses.

\section{References}

1. Zhang Deshun. Research and development of sound landscape abroad and Its Enlightenment to China, Journal of Tianjin Urban Architecture Institute.vol. 1,pp.6-9,(2013)

2. Li Guoqi. Soundscape announcement sound landscape research, Journal of Beijing Union University.vol. 1, pp.97-99,(2001)

3. Xian Yongjun. The significance and construction method of sound landscape,Interior design and decoration.vol. 5,pp.187,(2016)

4. Wang Kexin. Study on the experience of sound landscape, M.S. thesis.Hubei Institute of Fine Arts, Wuhan,China,(2016)

5. Zhang Dongxu. Soundscape in han Chinese buddhisttemples, Ph.D. dissertation,Harbin Industrial University,Harbin,China ,(2015)

6. Zhang Dahai. Factor analysis and entropy method for environmental evaluation of our past
construction,Accounting Monthly.vol. 18,pp.124130,(2019) 